\title{
Balkanologie
}

Balkanologie Revue d'études pluridisciplinaires

Vol. III, n² | 1999

Volume III Numéro 2

\section{Antébi (Elizabeth), Les missionnaires juifs de la France,} 1860-1939

Paris: Calmann-Lévy, 1999, 370 pages

\section{Bernard Lory}

\section{(2) OpenEdition}

\section{Journals}

Édition électronique

URL : http://journals.openedition.org/balkanologie/2191

DOI : 10.4000/balkanologie.2191

ISSN : 1965-0582

\section{Éditeur}

Association française d'études sur les Balkans (Afebalk)

Édition imprimée

Date de publication : 1 décembre 1999

ISSN : 1279-7952

\section{Référence électronique}

Bernard Lory, «Antébi (Elizabeth), Les missionnaires juifs de la France, 1860-1939 », Balkanologie [En ligne], Vol. III, n² | 1999, mis en ligne le 22 juin 2010, consulté le 17 décembre 2020. URL : http:// journals.openedition.org/balkanologie/2191 ; DOI : https://doi.org/10.4000/balkanologie.2191

Ce document a été généré automatiquement le 17 décembre 2020.

(c) Tous droits réservés 


\section{Antébi (Elizabeth), Les missionnaires juifs de la France, 1860-1939}

Paris: Calmann-Lévy, 1999, 370 pages

\section{Bernard Lory}

\section{RÉFÉRENCE}

Antébi (Elizabeth), Les missionnaires juifs de la France, 1860-1939, Paris : Calmann-Lévy, $1999,370 \mathrm{p}$.

1 Derrière ce titre un peu provocateur, Elizabeth Antébi se propose de nous raconter la vie d'une vingtaine d'enseignants de l'Alliance Israélite Universelle (AIU) entre 1860 et 1939. « Missionnaires », ils le furent, non pas du judaïsme, qui n'est pas une religion de prosélytisme, mais d'une certaine conception de la civilisation qu'ils allèrent diffuser loin de leur lieu de naissance, parmi leurs coreligionnaires juifs des Balkans, d'Afrique du nord ou du Proche-Orient. "Missionnaires de la France », peut-être, si l'on prend soin de dissocier l'État français, incarné par le Second Empire puis la Troisième République (lequel appuya plutôt mollement l'action de l'AIU), d'une vision quasi mythique de la France émancipatrice, égalitaire, universaliste, éclairée par la science et la raison, et dont la langue était censée avoir des vertus de clarté et de précision incomparables. C'est de cette France-là que se firent les missionnaires les personnages dont nous découvrons les destins mouvementés.

L'ouvrage ne se veut pas une histoire de l'Alliance Israélite Universelle, bien qu'au travers des récits de vie, toutes les phases et les crises que connut l'institution se trouvent évoquées: le Congrès de Berlin, l'affaire Dreyfus, la Première Guerre mondiale, la montée en puissance du sionisme, l'émergence des États nationaux successeurs des Empires.

3 Cinq destins sont explicitement liés à l'histoire de la zone balkanique. Celui d'Elie Nathan, instituteur à Istanbul qui affronte le déploiement du nationalisme turc sous le régime kémaliste; Rosalie Chéni qu'une carrière difficile mène de Jambol à Istanbul; 
Sarah Ungar, juive allemande, qui de 1890 à 1911 se consacre à l'éducation des filles à Edirne ; Moïse Cohen, installé dans une existence de notable à Plovdiv, qui reçoit de plein fouet la première vague du sionisme en 1901-1903; enfin, la figure de Joseph Nehama, le grand historien des juifs de Salonique, nous est présentée.

Il ne faudrait pas croire que l'intérêt balkanologique de l'ouvrage s'épuise avec ces cinq cas. Six autres biographies suivent la carrière de juifs originaires de la Péninsule, que le service de l'AIU enverra dans les destinations les plus variées. Yomtob Sémach, natif de Jambol, fut successivement instituteur à Sousse, Plovdiv, Tatar Pazardžik, Damas, Bagdad, Beyrouth, fit une mission exploratoire au Yémen, pour achever sa longue carrière au Maroc. Jacques Valadji, natif de Tatar Pazardžik, enseigna à Bagdad, Damas, Jérusalem, Izmir, Edirne, Meknes et Fez. Né à Karnobat, Albert Contino enseigna à Ispahan avant de devenir inspecteur de l'AIU en Algérie. Joseph Halévy, érudit de grand renom qui étudia les Falashas d'Éthiopie et explora le Yemen, était natif d'Edirne, de même qu'Ezra Menda, instituteur à Alep. Né à Šumen, Isaac Astruc enseigna à Damas et Ruse, et intervint courageusement en faveur des juifs de Bessarabie, victimes des pogromes de 1905. Enfin, au détour des chapitres ou des notes, nous rencontrons Maurice Sidi, né à Tatar Pazardžik, en poste à Mossoul, Joseph Almaleh de Čirpan, en poste à Ispahan et Tripoli, Joseph Niego d'Edirne en poste en Palestine, etc.

5 Si le cadre de l'Empire ottoman explique le champ d'action étendu de ces juifs de Roumélie, il faut souligner le paradoxe de ces «Bulgares» qui prennent à cœur la diffusion de la langue française parmi leurs coreligionnaires d'Algérie... citoyens français! Si l'influence de la culture française dans les Balkans a fait l'objet de multiples études ${ }^{1}$, la filière de diffusion de la langue et de l'« idéologie citoyenne » françaises par les écoles de l'AIU mérite de retenir notre attention. D'autant plus que l'AIU refusa toujours l'enfermement communautaire et ouvrit ses écoles à un certain nombre de non-juifs.

6 L'ouvrage d'Elizabeth Antébi laisse cependant un relent d'insatisfaction. Ce n'est pas son parti-pris biographique et donc forcément anecdotique, que l'on contestera, car il est plein de vivacité et permet de savoureuses citations de documents inédits, mais le côté hâtif et parfois bâclé de sa rédaction. Cela se marque dans des citations et paragraphes mal raboutés (p.60), une biographie laissée en suspens (celle d'Isaac Astruc, p. 267), des expressions incohérentes («battre en lisière», p. 168) et un vocabulaire peu orthodoxe («barquiers » au lieu de bateliers, p. 294 ; "vacherie » au lieu d'étable ou de laiterie, « sériculture » (sic) au lieu de magnanerie, p. 296). C'est bien mal honorer la mémoire de ces apôtres d'un français clair et rigoureux.

7 Les négligences dans les explications sont plus gênantes encore: Deuxième (au lieu de Première) Guerre mondiale (p. 144), influence soviétique (au lieu de russe, p. 168), pour aboutir à quelques énormités: Diyarbakır dans le Caucase (p.217), «Skopje est désormais une ville albanaise » (p. 354), etc.

8 La précipitation amène à formuler des jugements erronés sur le plan historique : « l'Alliance s'est retirée en 1936. En un lustre les sentiments antijuifs et pro-nazis de la Grèce n'ont fait que croître et embellir. Les déportations, à partir de 1941, en seront l'effroyable conséquence» (p. 208). S'il est exact que la dictature de Metaxas (août 1936 - janvier 1941) connut une dérive fascisante, on ne peut passer sous silence le fait que la Grèce combattit les forces de l'Axe, fut envahie, démembrée territorialement et connut un des mouvements de résistance parmi les plus actifs d'Europe. Le raccourci 
stylistique et le lien de cause à effet ici établi laisse clairement entendre que la déportation des juifs de Grèce aurait été une initiative grecque. C'est inadmissible ${ }^{2}$.

9 La précipitation dans l'écriture et l'absence de relecture critique de la part des maisons d'éditions rendent ce genre de dérapages malheureusement trop fréquents.

\section{NOTES}

1. Voir le récent numéro d'Études balkaniques de Sofia ou encore Makedonsko-francuski odnosi (Bitola, 1999, 485 p.).

2. On peut se reporter au chapitre que M. Mazower consacre à la "solution finale" en Grèce dans Mazower (Mark), Inside Hitler's Greece ,New Haven / London : Yale University Press, 1993. 